Archivum, LXX (I), 2020, pp. 229-254

\title{
El instinto de la literatura. Una aproximación a la actividad literaria a partir de la teoría de la evolución
}

\author{
José Manuel Ruiz Martínez \\ UNIVERSIDAD DE GRANADA \\ jmanuelruiz@ugr.es
}

Recibido: 19/06/2109

Aceptado: 04/11/2019

\section{RESUMEN:}

El presente artículo pretende discutir la posibilidad de pensar la literatura a partir de la teoría de la evolución. Haremos, pues, una exposición crítica de esta posibilidad, esto es, que la actividad literaria tiene que ver con facultades innatas, producto de la selección natural y la evolución humanas. Lo haremos a partir de los autores que, de forma directa, la han abordado, principalmente tres: Joseph Carroll, Steven Pinker y Denis Dutton. Para contextualizar el problema, pondremos todas estas ideas en relación con algunas reflexiones literarias (de autores y teóricos de la literatura) que han intentado dar cuenta de la cuestión acerca de la naturaleza del hecho poético o literario. Entre otras consecuencias, la propuesta tiene unas implicaciones sobre el debate acerca de las relaciones entre naturaleza y cultura, esto es: qué hay en el ser humano de cultural y por ende de relativo en su conducta, o bien de perteneciente a una naturaleza humana común a todas las culturas, y si un hecho a priori tan obviamente cultural como el literario puede considerarse a la luz de los las cualidades naturales del ser humano en cuanto especie animal producto de un sofisticado proceso de evolución. 
PALABRAS CLAVE: Teoría de la literatura, teoría de la evolución, naturaleza humana, teoría de la ficción.

The instinct of literature. An approach to literary activity from the theory of evolution

\begin{abstract}
:
This article aims to discuss the possibility of thinking about Literature from the perspective of the Theory of Evolution. We will therefore make a critical exposition of the possibility that literary activity has to do with innate faculties, product of natural selection and human evolution. We will do so using three main authors who have directly approached this idea: Joseph Carroll, Steven Pinker, and Denis Dutton. In order to contextualize the problem, we will put their ideas in relation to some literary ideas (from literary authors and literary theorists) that have tried inquire about the nature of the poetic or literary facts. Among other consequences, the proposal has implications on the debate about the relations between nature and culture, that is: what is cultural in the human being, and therefore relative in his or her conduct, what belongs to a common human nature, and also if an activity so obviously cultural as Literature can be considered in the light of the natural qualities of the human being as an animal species product of a sophisticated process of evolution.
\end{abstract}

KEY WORDS: Literary Theory, Evolutionary Theory, Human Nature, Theory of Fiction.

\title{
1. Introducción
}

En una paráfrasis del provocativo título de Denis Dutton El instinto del arte (2009), el presente artículo pretende discutir la posibilidad de pensar la literatura a partir de la teoría de la evolución. La idea subyacente a la propuesta es que, si la vida tiene una base biológica, el conocimiento y, por ende, el quehacer literario en cuanto actividades que realiza el ser humano vivo, también la tienen (Carroll, 1995, 77). Es decir: no puede aislarse la literatura o la teoría cultural (el ámbito de las humanidades) de sus fundamentos biológicos, $\mathrm{y}$, por consiguiente, de una explicación de estas de carácter biológico (siquiera en su origen). En definitiva, se trata de explorar la posibilidad de que "la historia 
y la cultura se pueden asentar en la psicología, y ésta, en la computación, la neurociencia y la evolución" (Pinker, 2002,115). La idea de la base biológica del pensamiento y otras actividades mentales (psicológicas) análogas se fundamenta en la 'teoría computacional de la mente' (Pinker, 2002, 60-74), cuya premisa es que el mundo mental (el aprendizaje o la memoria, por ejemplo) se asienta en el mundo físico, y que dicha base puede explicarse a través de conceptos como información, computación y retroalimentación (Pinker, 2002, 61). Para el caso concreto que nos ocupa, se trata de evitar el movimiento teórico habitual de identificar la literatura "with a realm of the spirit, and to segregate this realm from the objectively knowable world" (Carroll, 1995, 31). Entre otras consecuencias, la propuesta tiene unas implicaciones controvertidas sobre el debate acerca de las relaciones entre naturaleza y cultura, esto es: qué hay en el ser humano de cultural y por ende de relativo en su conducta, o bien de perteneciente a una naturaleza humana común a todas las culturas, y si un hecho a priori tan obviamente cultural como el literario puede considerarse a la luz de las cualidades naturales del ser humano en cuanto especie animal producto de un sofisticado proceso de evolución. En efecto, la consideración de la literatura (y actividades humanas similares) desde un punto de vista evolutivo presupone que la denominada naturaleza humana no es una tabla rasa o página en blanco, es decir, "la idea de que la mente humana carece de una estructura inherente y que la sociedad y nosotros mismos podemos escribir en ella a voluntad" (Pinker, 2002, 23), y que esto determina la conducta $-\mathrm{y}$ donde por ende bastaría con borrar o, mejor aún, escribir ex novo determinados elementos para modificar el comportamiento humano, que sería eminentemente manipulable - , sino que implica un sofisticado conjunto de aptitudes innatas (una suerte de cableado natural) y propensiones que han evolucionado a través de un proceso adaptativo regido por la selección natural; frente a esta teoría, la idea de la tabla rasa se fundamenta en un milagro: "una mente compleja que surge de la nada" (Pinker, 
2002, 23). En este sentido, "human motives, ideas, and cultural practices are fundamentally directed and constrained by innate characteristics" (Carroll, 1995, 25). La idea de que "la mente es un sistema de módulos computacionales generativos universales" (Pinker, 2002, 74) implica una verdadera revolución frente a la hipótesis de la mente como una tabla rasa y la hipótesis de un libre albedrío radical, así como de un no menos radical relativismo cultural. Según Pinker,

los seres humanos se comportan flexiblemente porque [...] sus mentes están equipadas con el software combinatorio que puede generar un conjunto ilimitado de pensamientos y de conductas. La conducta puede variar bastante entre las culturas, pero el diseño de los programas mentales que la generan no tiene por qué variar. (Pinker, 2002, 74; cursiva del autor)

En la ya citada contraposición entre naturaleza y cultura o medio, no se trata en ningún caso de erradicar, ni siquiera de minusvalorar, la importancia de estos dos últimos elementos en la configuración del ser humano y de sus actividades (incluida, no lo perdamos de vista, la literaria): la explicación de nuestra conducta suele hallarse "en una interacción compleja entre la herencia y el medio: la cultura es esencial, pero no podría existir sin unas facultades mentales que permiten que los seres humanos construyan y aprendan la cultura" (Pinker, 2002, 13). En definitiva, según Pinker, existen razones para pensar que

la mente está equipada con una batería de sentimientos, impulsos y facultades para razonar y comunicarse, y que tienen una lógica común en todas las culturas, son difíciles de eliminar o de rediseñar a partir de cero, fueron configuradas por la acción de la selección natural en el transcurso de la evolución humana y deben algo de su diseño básico (y de su variación) a la información presente en el genoma. (Pinker, 2002, 122) 
En el presente artículo pretendemos, pues, hacer una exposición crítica de esta posibilidad, esto es, que la actividad literaria constituye (o al menos se relaciona directamente) con este tipo de facultades innatas, producto de la selección natural y la evolución humanas. Lo haremos a partir de los autores que, de forma directa, la han abordado, principalmente tres: Joseph Carroll, Steven Pinker (a quienes ya hemos citado varias veces) y el ya mencionado Denis Dutton. Para contextualizar el problema, pondremos todas estas ideas en relación con algunas de las teorías literarias que, desde Aristóteles hasta Shklovski, han intentado dar cuenta de la escurridiza cuestión acerca de la naturaleza del hecho poético o literario. Porque uno de los aspectos más interesantes de este acercamiento es que acaba apuntando a unas cualidades concretas del mismo y, por consiguiente, parece dar la razón a determinadas teorías o concepciones de lo literario en detrimento de otras.

\section{La literatura como facultad adaptativa producto de la evolu- ción}

Como constatan tanto Carroll como Dutton, no parece haber mucha relación entre una teoría, la de la evolución, que sirve para explicar la fisiología y la conducta animal (y, por ende, la humana), con las estructuras verbales de carácter imaginativo a las que de forma convencional denominamos como literatura: "the relevance of biology to literary theory is by no means selfevident" (Carroll, 1995, 1). ¿Qué tienen que ver características físicas humanas como el funcionamiento de los órganos o, por ejemplo, el origen de nuestros pulgares contrapuestos, con la creación de obras de arte verbal? (Dutton, 2009, 13-14). Si hablamos de instinto, parecemos estar aludiendo a comportamientos inconscientes en un sentido estricto del término, de carácter automático y uniforme: nada más alejado de la realización consciente y única que, en principio, atribuimos a las obras de arte: "cada miembro de una especie de araña tejedora de telas produce básicamente la misma red a partir del mismo código 
que los otros miembros de su especie" (Dutton, 2009, 14); frente a esto, "las artes se caracterizan por su peculiaridad. Aúnan distintas tradiciones, géneros, la experiencia íntima del artista, la fantasía, la emoción, todo ello fusionado y transformado en la imaginación estética" (Dutton, 2009, 14).

Pues bien, la idea que subyace a esta teoría es que la actividad literaria sería un producto de la evolución, un resultado evolutivo más, consecuencia del proceso de adaptación al medio operado en los seres humanos. Según esta hipótesis, a lo largo del último millón de años de evolución, esta no solo nos proporcionó, por ejemplo, unos determinados órganos visuales extremadamente complejos, sino también la posibilidad de crear determinadas experiencias que podríamos denominar, grosso modo, literarias, desde juegos infantiles, o de palabras, y chistes, hasta las novelas o el poema más experimental:

La evolución del Homo sapiens a lo largo del último millón de años no es sólo una crónica de cómo obtuvimos una visión aguda en color, desarrollamos el gusto por los alimentos dulces y aprendimos a caminar erguidos. También es la historia de cómo nos convertimos en una especie obsesionada por la creación de experiencias artísticas con las que divertirnos, sorprendernos, cautivarnos y hacernos dudar. (Dutton, 2009, 15)

Pero, ¿cómo se convierte la actividad literaria exactamente en un resultado de la evolución de los seres humanos en cuanto especie animal? ¿Qué función cumpliría? Según Carroll, la actividad literaria estaría relacionada con la necesidad humana de, en primer lugar, percibir el entorno y, después, relacionarse con él de forma que la supervivencia quede garantizada (atisbando, o incluso previendo, la presencia de depredadores, por poner un ejemplo evidente) (Carroll, 1995, 2-3). Por lo que respecta a la base biológica de esta operación, Carroll la plantea en forma de silogismo: "knowledge is a biological phenomenon, [...] literature is a form of knowledge, and [...] literature is thus 
itself a biological phenomenon" (Carroll, 1995, 1). Antes nos hemos referido al ojo humano como una muestra señera de la actividad adaptativa propiciada por la teoría de la evolución. Pues bien, el ojo, en realidad, no cumple ninguna función mecánica o química para el cuerpo. Se trata de un órgano dedicado a proporcionar información para ser procesada: "Its function is to use the reflection of light to construct cognitive models of the local three-dimensional world" (Carroll, 1995, 97). En este sentido, y a partir del concepto biológico fundamental de que la naturaleza y las actividades de los seres vivos se explican en su relación con el entorno, Carroll recuerda que una de las formas de adaptación de un organismo a su entorno consiste en la elaboración de representaciones como formas de "cognitive mappings" que, ante todo, son físicos y espaciales (Carroll, 1995, 2). La idea de cognitive mapping, esto es, de "cartografía cognitiva", no sería aquí una metáfora para una actividad cognitiva abstracta (Carroll, 1995, 2), sino que, por el contrario, "abstract activities are, rather, an extension of the primary cognitive function that locates the organism within its concrete, physical environment" (Carroll, 1995, 2-3). ${ }^{1}$ En palabras de Pinker, esta capacidad de elaborar cartografías cognitivas se explica como una serie de facultades innatas que incluye, entre otras, el citado sentido para orientarnos en el espacio físico y reconocer los objetos; la capacidad de entender y construir artefactos; la de establecer probabilidades y anticiparnos a lo que pueda suceder; la posibilidad de percibir y comprender a los otros seres humanos, sus conductas, sus motivaciones y sus reacciones; la capacidad para representar ideas y encadenarlas en procesos lógicos de deducción y respuesta a preguntas como 'qué', 'quién', 'a quién', 'dónde', 'cómo', 'cuándo', 'por qué’; y, por último, el lenguaje, con el que compartimos dichas ideas, así como el resto de nuestras percepciones (Pinker, 2002, 325).

1 Usamos aquí el término 'cognitivo' no en su acepción común de razonamiento frente a emoción o procesos irracionales, sino para referirnos a cualquier proceso psicológico, incluyendo la emoción y la percepción. 
Esta noción de cartografía cognitiva no implica, no obstante, un planteamiento ingenuo de la percepción ni la psicología: no quiere decir que el mundo exista y nosotros lo percibamos con los sentidos en una correspondencia inmediata a través de estas facultades y que luego lo podamos plasmar con absoluta fidelidad a través del lenguaje. Quiere decir, sencillamente, que las citadas facultades han ido evolucionando para percibir el entorno. Nuestro cerebro, a partir de estas, elabora un constructo que, evidentemente, no es la realidad; pero no es un constructo arbitrario producto de categorías o sesgos culturales (Pinker, 2002, 296): " "nuestro sistema perceptivo está diseñado para registrar aspectos del mundo exterior que fueron importantes para nuestra supervivencia, como los tamaños, las formas y los materiales de los objetos" (Pinker, 2002, 296). De hecho, por poner un ejemplo ceñido a la percepción visual y espacial, la mayor parte de las ilusiones ópticas con las que se pretendería demostrar cómo nos engañan nuestros sentidos, vienen en realidad a probar que el sistema funciona, solo que lo hace para aquello para lo que evolucionó, dado que, en la mayoría de las citadas ilusiones, el cerebro está interpretando imágenes bidimensionales como si fueran tridimensionales, es decir, las percibe como provenientes de un entorno real (Pinker, 2002, 297). Nuestro cerebro, en definitiva, - aunque el devenir de la cultura occidental nos haga tener esta idea-no fue evolucionando para comprender el mundo en abstracto, ni para indagar en los misterios últimos de la existencia, aunque ahora, 'además', le demos esa función: lo hizo para percibir el entorno físico inmediato $y$, a partir de lo percibido, buscar soluciones vinculadas con la supervivencia

2 En este sentido, las teorías científicas que explican la conducta humana en términos de psicología evolutiva implican un cuestionamiento radical de las (en general) teorías de corte postestructuralista que postulan la configuración o creación del sentido, o de la propia realidad, a través del lenguaje, negando la posibilidad de representación objetiva de éste. Buena parte del libro de Carroll (1995) constituye, de hecho, una crítica a todas las teorías de este tipo, con especial atención a Foucault, Derrida y los deconstruccionistas, Eagleton, la posmodernidad y el nuevo historicismo. También Pinker (2002) dedica bastantes páginas al cuestionamiento de este tipo de teorías, así como las ideas más radicales de relativismo cultural. 
y la reproducción. En efecto, “algunas de nuestras perplejidades pueden proceder de un desajuste entre los objetivos para los que evolucionaron nuestras facultades cognitivas y los objetivos que hoy les asignamos" (Pinker, 2002, 323). En este mismo sentido, el lenguaje no es un reflejo fiel en términos absolutos de la realidad, pero nos ayudó en su desarrollo evolutivo a comunicarla de modo eficaz en términos de cooperación y supervivencia.

Es en este contexto donde Carroll plantea su hipótesis de que la literatura no sería sino una derivación particular de esas formas de cartografía cognitiva con las que los seres humanos nos orientamos en el mundo: "literary works reflect and articulate the vital motives and interests of human beings as living organisms" (Carroll, 1995, 3). En este sentido, "literature is a mental product, and the adaptive function of the mind is to locate the organism in its environment" (Carroll, 1995, 104). La actividad literaria, por tanto, al igual que otras formas de representación, constituiría "una forma de conocimiento" cuya especificidad sería la experiencia humana en cuanto percepción subjetiva (Carroll, 1995, 104-105): "in literature, these activities are typically subordinated to the purpose of representing the subjective sense of human life" (Carroll, 1995, 105). La representación de la experiencia subjetiva es la principal característica específica de esta forma de conocimiento en relación con otras, como la científica: "Literature is different from science [...] in that it seeks to convey the subjective quality of experience" (Carroll, 1995, 106); también en que busca obtener una respuesta personal, igualmente subjetiva, en el receptor (Carroll, 1995, 105). Sí tendría en común con la ciencia, la filosofía y las disciplinas humanísticas, como es lógico, el uso del lenguaje, solo que su aportación particular es conseguir la representación de la citada experiencia subjetiva a través de un uso particular del lenguaje, dotado de peculiaridades rítmicas y estéticas (Carroll, 1995, 106107). ${ }^{3}$ Desde este punto de vista, Carroll define las obras literarias

3 Aquí Carroll, sin mencionarlo, expone ideas análogas a las clásicas de Jakobson al respecto en Lingüística y poética (1981) sobre el predominio de la función poética y su reflejo en el lenguaje. 
as representations that either take the quality of personal experience as their special subject or register the writer's own sense of the experiential quality of his or her subject, that are intended to stimulate emotional and aesthetic as well as conceptual responses in the reader, and that are constructed of words rather than, say, of numerical formulas or pictorial simulacra. (Carroll, 1995, 109)

Carroll entiende esta definición como meramente formal, sin que haya que remitirse a una suerte de esencia platónica de la literatura o las obras literarias, por lo que admite que esta definición, si bien acota un campo de estudio sustancial y distinto, presenta unos límites poco claros en los que formas análogas que convencionalmente no se consideran literarias podrían tener cabida: "Literature need not be submerged in other fields nor rigidly segregated from them" (Carroll, 1995, 109), pero es que no es posible entender la literatura sin el estudio de sus relaciones con otras actividades afines (Carroll, 1995, 110). ${ }^{4}$

En realidad, la idea de la literatura como una forma de conocimiento no es nada ajena a la propia reflexión que la teoría literaria ha ido construyendo en torno a su objeto de estudio al margen de la ciencia y de la teoría de la evolución; constituye de hecho, un lugar común de la reflexión literaria. Pensemos, sin ánimo de ser exhaustivos, que ya Aristóteles catalogaba el arte entre los cinco modos diferentes de conocimiento existentes $-\mathrm{y}$ la poesía constituía un arte- (Bobes Naves, 2008, 54). O en autores como Cassirer, quien, por su parte, entiende que las formas que nos permiten comprender el mundo son las simbólicas, y entre estas se cuentan el mito y el arte a la par que el propio lenguaje o el conocimiento mismo (Bobes Naves, 2008, 145). Por su

4 Uno de los problemas del planteamiento de Carroll es que no hace ninguna consideración epistemológica acerca de la noción de literatura. Fundado en esta idea de definición formal, da por hecho su objeto de estudio y comienza a teorizar sobre él. Para la cuestión de la epistemología literaria y un cotejo con las teorías de Carroll, Chicharro (1987) y Bobes Naves (2008). 
parte, Dupont, acerca de los orígenes mismos de la literatura en los rapsodas griegos, obseva:

la verdad del mundo sólo es accesible a los hombres desde el interior de su realidad humana, a través de las contingencias de tiempo, lugares y personas. Nada existe ni acá ni acullá del accidente. El aedo revela, pues, a los hombres las conexiones invisibles que, en el acontecimiento, organizan la cultura de los hombres. $(1994,24)$

En lo que suelen considerarse los orígenes de la teoría de la literatura en el siglo xx (Wahnón, 1991, 71), el formalismo ruso, que no en vano constituye un intento de acercamiento 'científi$\mathrm{Co}^{\prime}$ al hecho literario al margen de su historicidad, resulta muy reveladora en relación con la tesis de Carroll la caracterización que hace Shklovski de la imagen poética (para cuestionar la idea recibida de la generación crítica anterior acerca de la literatura como forma de pensamiento); para Shklovski, las imágenes que encontramos en la poesía presentan más bien cualidades eminentemente perceptivas, no de cognición abstracta, sino de una relación directa y vital con el medio (y así se desprende de los verbos que emplea, todos ellos vinculados con la experiencia sensorial): "para dar sensación de vida, para sentir los objetos, para percibir que la piedra es piedra, existe eso que se llama arte" (1965, 60). Para Shklovski, la finalidad del arte (en cuanto creador de imágenes y donde, por supuesto, se incluye la poesía), frente a una percepción automatizada que acabaría por volver las cosas del entorno invisibles de puro rutinarias, consiste en aumentar la duración de la percepción: "el acto de percepción es un fin en sí y debe ser prolongado" $(1965,60)$. Tras esta definición, Shklovski indica algunas formas para contemplar mejor las cosas representadas por la literatura, para liberarlas del automatismo perceptivo: por ejemplo, la singularización, la descripción exhaustiva o la descontextualización (Shklovski, 1965, 62-68). Por su parte, Lotman, en su presentación a la Estructura del texto artístico (1970), ya reconoce que el arte ha acompañado al ser humano desde sus 
orígenes y que, incluso, “entregado a la lucha por la conservación de la vida, desprovisto casi siempre de lo estrictamente necesario, el hombre encuentra invariablemente tiempo para dedicarse a la actividad artística, siente su necesidad" $(1970,9)$ para, a continuación, vincular dicha necesidad con la de conocimiento, dado que "el arte es una forma de conocimiento de la vida, de la lucha del hombre por la verdad que le es necesaria" (1970, 10). Pero es quizá la poética generativa la que, como heredera de la lingüística generativa y la idea de los universales lingüísticos (tan defendidos, por ejemplo, por Pinker), al postular una competencia poética entendida como capacidad humana para generar y comprender estructuras poéticas (Asensi, 2003, 283-287), aparece como más cercana a las ideas evolucionistas. Por último, no querríamos dejar de mencionar cómo, desde el humanismo historicista, también se ha buscado la raíz de unos universales teóricos (estéticos) que subyacerían en la obra literaria y que tendrían un origen antropológico: es el orden que, según Northrop Frye, se da en el hecho literario y que permitiría, según este crítico, un acercamiento teórico sistemático a éste $(1977,33)$; o la conocida (y combativa) reivindicación de la autonomía y universalidad de lo estético de un Harold Bloom. Incluso en un planteamiento teórico que parece contradecir desde su relativismo radical estos postulados, como es el de Paul de Man, García Berrio ha percibido que, de llevar sus paradojas hasta sus últimas consecuencias, se puede percibir en él un universalismo retórico tras el que se perfilan "los trayectos lógicos universales [...] que constituyen la percepción de la realidad" (García Berrio, 1994: 66).

También desde el punto de vista de los propios autores literarios, Milan Kundera, en su ensayo El arte de la novela (1986), en relación con el oficio del novelista dice de este que "no es un historiador ni un profeta: es un explorador de la existencia" $(1986,56)$; y percibe la novela misma como una indagación existencial, que moviliza "sobre la base del relato, todos los medios, racionales e irracionales, narrativos y meditativos, que pudieran iluminar el ser del hombre" $(1986,96)$. Para Kundera, la historia 
de la novela moderna desde Rabelais y, sobre todo, Cervantes, es la exploración progresiva sobre diferentes aspectos de la existencia humana: el viaje, la aventura, el juego, el sueño, el tiempo; la acción, la intimidad, el mundo interior (y su relación con la acción, con las acciones). Y, por ejemplo, al hablar de la tarea exploratoria que acomete la ficción de Joyce sobre la naturaleza del tiempo y el momento presente - por contraposición a la del recuerdo, el 'tiempo perdido' de Proust- Kundera usa la metáfora del "microscopio" de Joyce bajo el cual se observa al yo (Kundera, 1986, 35).

Pero es quizá Henry James quien, en sus reflexiones acerca del arte de la novela que esboza en el prólogo de El retrato de una dama, nos proporciona algunas intuiciones que guardan una sugestiva y clara analogía con las tesis de Carroll acerca de la literatura (la ficción, de nuevo, en este caso, como la creación de un mapa cognitivo de carácter intersubjetivo con el que comprender mejor el mundo):

La casa de la ficción tiene, en resumen, no una sino un millón de ventanas, un número de posibles ventanas inimaginable, en realidad, cada una de las cuales ha sido abierta, o puede todavía abrirse, en la vasta fachada, por la necesidad de la visión individual [...]. No son puertas que se abren directamente a la vida. Pero tiene la característica propia de que ante cada una de ellas se alza una figura con un par de ojos, o al menos, con unos gemelos, que las convierte una y otra vez, con fines de observación, en un instrumento único que proporciona a quien lo usa una impresión distinta cada vez. (James, 2007, 83)

Asimismo, el poeta Wallace Stevens identifica la "verdad poética" como "an agreement with reality, brought about by $[\ldots]$ a man disposed to be strongly influenced by his imagination, and expressed in terms of his emotions or [...] in terms of his own personality" (Carroll, 1995, 105).

¿Cuál es por tanto la aportación novedosa de autores como Carroll o Dutton acerca de las potencialidades cognitivas 
de la actividad literaria? Justamente la que vincula dichas potencialidades cognitivas con una cualidad innata producto de la evolución: la especificidad evolutiva de la actividad literaria como forma de conocimiento del mundo, cuya consecuencia principal sería el hecho de postular que esta constituya (reducida, claro, a sus rasgos fenomenológicos más básicos - los de la propia definición formal de Carroll dada más arriba-), un genuino universal cultural no sometido a la contingencia de la Historia, sino caracterizado como un impulso derivado de unas facultades innatas de las que se fueron configurando a través de la selección natural: la necesidad de comprender el mundo a través de su representación mediante el lenguaje, representación que va más allá de la mera necesidad comunicativa y que implica cualidades rítmicas estéticas, subjetivas, etc., aun cuando, por supuesto, sean luego (pero siempre luego) las diferentes culturas y el devenir histórico e ideológico los que van modulando, variando y sofisticando, este impulso inicial para ir configurando las diferentes manifestaciones literarias a lo largo de la Historia, tan distintas, e incluso contradictorias entre sí.

\section{Planteamiento crítico de la cuestión}

La idea de la actividad literaria como una actividad innata producto de la adaptación al medio y surgida de la necesidad de comprender el entorno - más allá de sus manifestaciones concretas, históricas, culturales, ideológicas - no parece difícil de entender; incluso no parece difícil de aceptar, siquiera de forma genérica: pasado el instante más virulento de las teorías más radicalmente relativistas, aquél en el que, en palabras de García Berrio, se daba el hábito "lamentable y generalizado" de "reaccionar apasionadamente contra la simple mención de los universales expresivos y estéticos", lo que provocaba "de entrada los peores prejuicios" $(1994,57)$, la idea de los universales culturales, por mor de los progresos actuales en psicología evolutiva o en teoría de la comunicación $(1994,58)$ está cada vez más asentada, y existe un consenso razonable en la existencia, en las diferentes culturas humanas, de 
rasgos más allá de las cuestiones naturales más básicas (como la danza, el ritmo, etc.), por lo que sumar a ellos la representación imaginativa y poética del mundo en un sentido muy amplio y abarcador no resulta inverosímil (Pinker, 2002, 627-632). Esta teoría comienza incluso a cundir entre los propios autores literarios. Cabe destacar en este sentido el ensayo del escritor mexicano Jorge Volpi, Leer la mente. El cerebro y el arte de la ficción (2011), cuya premisa es exactamente esta del origen y la explicación en términos evolutivos y de adaptación de la ficción literaria. Para Volpi, en efecto, como expone en su libro, el arte tiene esta cualidad adaptativa, cuya utilidad es similar a la de, por ejemplo, la construcción de herramientas: "un juego evolutivo con patrones, provisto de información socialmente relevante" (Volpi, 2011, pos. 403) Su tesis - en realidad, la que estamos discutiendo aquí- se resume en el siguiente párrafo, referido únicamente a la ficción pero extensible a todo el hecho literario y al arte en general:

La ficción literaria debe ser considerada una adaptación evolutiva que, animada por un juego cooperativo, nos permite evaluar nuestra conducta en situaciones futuras, conservar la memoria individual y colectiva, comprender y ordenar los hechos a través de secuencias narrativas $y$, en última instancia, introducirnos en las vidas de los otros, anticipar sus reacciones y descifrar su voluntad y sus deseos. $(2011, \text { pos. } 417)^{5}$

La idea, tal y como la plantea Volpi, es, en esencia, correcta si aceptamos como válida la teoría del origen evolutivo de la actividad literaria. El problema, claro, es que la cuestión a la postre no resulta tan sencilla más allá del modo divulgativo o ensayís-

5 En realidad, la facultad para tratar de anticipar las reacciones de nuestros semejantes e intentar descifrar su voluntad y sus deseos, ya se considera una de las facultades innatas de nuestro cerebro obtenidas gracias a la evolución. Pinker habla de una "psicología intuitiva, que utilizamos para comprender a las demás personas" (Pinker, 2002, 325). Desde este punto de vista, la ficción artística solo serviría para reforzar y entrenar esta capacidad. 
tico. En la comunidad científica hay un consenso básico acerca de la teoría de la evolución como explicación del origen de cómo somos, pero no en cómo se sustancia y cuáles son sus límites. Este no es el lugar para desarrollar todos los problemas y las polémicas que la teoría de la evolución en relación con el comportamiento humano (la denominada psicología evolutiva) plantea. No obstante, vamos a señalar alguna de las cuestiones principales con las que se puede matizar la consideración de la actividad literaria como producto de la adaptación evolutiva y, a partir de aquí, exponer finalmente la hipótesis en toda su amplitud.

\subsection{Algunas premisas importantes de la teoría evolutiva}

Para empezar, hay que tener en cuenta algunas premisas fundamentales que, para las personas no especializadas en teoría de la evolución, podrían pasar inadvertidas y dar lugar a equívocos. La primera de ellas es que, si bien la evolución parece obedecer a un diseño, pues los organismos se van modificando y sus capacidades se perfilan en relación con el entorno, se trata de "un diseño ciego y aleatorio distinto a los procesos conscientemente intencionales" (Dutton, 2009, 125). En palabras de Pinker, el "diseño" o "propósito" evolutivo es un "simulacro de ingeniería" (Pinker, 2002, 89): los ojos parecen estar diseñados para percibir, las alas para volar, pero nada de esto se configuró con ese propósito a priori desde el inicio. En este sentido, volvemos a señalar lo contraintuitivo de considerar procesos mentales tan sofisticados como los que se ponen en marcha a la hora de elaborar obras literarias con unos orígenes puramente azarosos. La explicación es la selección natural, "el único proceso físico que conocemos que pueda simular procesos de ingeniería" (Pinker, 2002,90 ), porque la mejora de un determinado órgano, proceso o percepción contribuyó a la supervivencia o reproducción de su portador y por consiguiente se transmitió a sus sucesores. Por esto mismo, también resulta fundamental comprender que no basta que un determinado rasgo de conducta sea beneficioso o útil para la especie, o mejore su calidad de vida, o genere una 
armonía entre esta y su medio ambiente para que sea susceptible de ser considerado como adaptativo, sino que este tuvo que "tener como objetivo estricto la supervivencia o la reproducción" (Dutton, 2009, 126; Pinker, 2002, 91). De hecho, al no existir, según hemos dicho, un diseño previo del dispositivo, en ocasiones la necesidad de supervivencia y la de reproducción generan interferencias: un ejemplo clásico es el del pavo real, cuyas pesadas y ostentosas plumas se desarrollaron porque fueron exitosas en términos reproductivos - atraían a las hembras - si bien para la supervivencia (la huida frente a un depredador) resultan contraproducentes (Pinker, 2002, 590). En definitiva, "la adaptación se trata de una característica heredada, psicológica, afectiva o de conducta, que se acaba desarrollando en un organismo, de modo que incrementa sus posibilidades de supervivencia y reproducción" (Dutton, 2009, 132). Por tanto, la justificación en términos evolutivos y de adaptación de un hecho como la actividad literaria no puede basarse solamente en sus beneficios evidentes para el grupo humano en donde se practica (Dutton, 2009, 127); no vale la falacia silogística de decir "las adaptaciones evolutivas son ventajosas para nuestra especie. Las artes son ventajosas para nuestra especie. Por tanto, las artes son adaptaciones evolutivas" (Dutton, 2009, 127): hay que mostrar que las artes, o la literatura, implican una ventaja evolutiva para la especie en términos de supervivencia o reproducción, cuestión que abordaremos más adelante.

Por último, para evitar posiciones reduccionistas (que son las que alimentan las caricaturas deterministas de la teoría evolutiva), también hay otra importante cuestión a tener en cuenta: en lo que se refiere a la explicación evolutiva de la conducta, hay que distinguir entre causas "próximas" y causas "últimas" (Pinker, 2002, 93-94; Carroll, 1995, 2; Dutton, 2009, 138-132). Las causas últimas son las que condujeron a la supervivencia y reproducción de nuestros ancestros en su medio; también son los principios adaptativos que conducen a las causas próximas, que son la motivación real, concreta y actual de nuestra con- 
ducta (Pinker, 2002, 93). Las causas últimas son el germen, a veces oscuro e incluso contradictorio, de nuestra conducta actual. Hoy en día, sobre todo en medios poco extremos y hostiles (los cuales, por fortuna, se han generalizado), los seres humanos no luchan de modo continuo y literal por su supervivencia, si bien algunas conductas perjudiciales contemporáneas (como, por ejemplo, el estrés) pueden explicarse por esta causa última de la lucha por la supervivencia. Por lo mismo, los seres humanos no están tampoco pugnando activamente en la actualidad por reproducirse - en muchas ocasiones es más bien al contrario-; de ser así, nos sería literalmente imposible el empleo de los métodos anticonceptivos, que nos provocarían un rechazo instintivo (Pinker, 2002, 92). Se trata más bien de que las estructuras psicológicas humanas han evolucionado "under the regulative power of reproductive success and [...] these innate structures remain fully active at the present time" (Carroll, 1995, 2). Así, la causa última de la reproducción nos ha conducido, de forma paradójica, a toda una serie de causas próximas que nos llevan a desear el sexo y a practicar actividades sexuales prescindiendo de su finalidad reproductiva, y en cuyo desarrollo ha desempeñado un papel fundamental el devenir histórico, social y cultural de los seres humanos (lo que denominamos como 'erotismo'); y no obstante, el motor inicial de toda esa compleja amalgama de comportamientos, a veces, como decimos, incluso antirreproductivos, es la búsqueda instintiva de la reproducción. De forma análoga, la práctica literaria (o artística en general), en el caso de que tuviera un origen evolutivo, no estaría motivada, en sus distintas plasmaciones y su evolución histórica, por una causa última de forma directa, sino por multiplicidad de causas próximas que, estas sí, tienen que ver directamente con el medio, el devenir histórico, la cultura y la ideología. Solo, según hemos dicho, como un germen primero y oscuro, diluido en toda la complejidad posterior, podríamos considerar ciertos aspectos adaptativos como causa última de la actividad literaria. Esta distinción es importante porque, como 
hemos apuntado, despeja cualquier posible acusación que pueda hacérsele a esta hipótesis de reduccionismo o determinismo.

\subsection{Qué es adaptativo y qué no lo es: el riesgo del hiperadap- tacionismo}

Dadas las premisas y hechas las precisiones del apartado anterior, el principal problema al que se enfrenta la hipótesis de que la actividad literaria sea producto de la adaptación evolutiva es que, a partir de ciertos mínimos, ni los propios biólogos o psicólogos evolutivos se ponen de acuerdo en qué cualidades físicas, elementos constitutivos de la biología humana, o bien rasgos psicológicos, o de comportamiento, constituyen adaptaciones directas. No todo lo que se produce por un proceso adaptativo lo es. Puede deberse también a un efecto accidental (producto, por ejemplo, de una mutación aleatoria que consigue sobrevivir sin haber contribuido con ninguna ventaja a ello), o ser consecuencia de una adaptación o de un conjunto de adaptaciones (Dutton, 2009, 132). Este tipo de mutaciones dependen por tanto de la evolución "pero no son rasgos pautados que conforman su resultado final” (Dutton, 2009, 132). Un ejemplo característico de estos rasgos secundarios, no directamente adaptativos, lo constituye el color blanco del hueso. Existe una razón adaptativa para que el hueso sea fuerte, y su fortaleza la acabó extrayendo del calcio, que obtenemos de la nutrición; la blancura es tan solo una consecuencia de la composición química del hueso. Otro ejemplo típico son los pezones de los varones, consecuencia de una fisiología embrionaria compartida con las mujeres, cuyos pezones, por el contrario, sí cumplen una función básica y sí son un producto adaptativo directo (Dutton, 2009, 132-133). A partir de esta idea, algunos investigadores tratan de reducir la influencia de la adaptación evolutiva en la configuración de los seres vivos para, a partir de algunos elementos mínimos, entender los otros por derivación (Dutton, 2009, 134-139). Es el caso del biólogo Stephen Jay Gould, quien considera que, en el ámbito de la conducta humana, el único producto de la adaptación es el cere- 
bro humano y su tamaño anómalo (Gould, 1995, 50-52). Es esta premisa evolutiva fundamental la que habría dado lugar a una multitud de "epifenómenos" que, por tanto, serían consecuencias de azarosas de adaptaciones pero no adaptaciones mismas:

la selección natural favoreció el aumento del tamaño cerebral por un puñado de razones ligadas a la vida en las sabanas africanas. Pero, en virtud de esa potencia de cálculo, el cerebro puede hacer miles de cosas que no tienen nada que ver con las presiones selectivas que le hicieron aumentar de tamaño en primera instancia. $(1995,52)$

Para Gould, incluso el lenguaje, admitido por la mayor parte de psicólogos evolutivos como una consecuencia directa de la evolución, sería una de estas consecuencias accidentales (una especie de premio casual y maravilloso) de tener un cerebro demasiado grande (Pinker, 1995, 223). Por tanto, para este autor, ni la actividad literaria ni las actividades artísticas - a diferencia de para Dennis Dutton que sí lo son - serían producto de la evolución sino tan solo epifenómenos residuales (si bien, insistimos, asombrosos en su enriquecimiento de la vida humana) de un cerebro demasiado grande cuyo crecimiento sí obedeció a una causa adaptativa. Se trata de una postura que trata de frenar una tendencia 'hiperadaptacionista' que percibe rasgos evolutivos en cualquier elemento o conducta susceptible de ello. Como ha señalado Steven Pinker, "resulta erróneo inventar funciones para actividades que carecen de diseño [adaptativo] solo porque queremos ennoblecerlas con el sello de la adaptación biológica" (en Dutton, 2009, 139).

En este sentido, Pinker apuesta por una opción intermedia que resulta muy interesante para el caso que nos ocupa. Frente a quienes consideran que el arte es una adaptación evolutiva al mismo nivel que el miedo o la capacidad de visión espacial, él opina que se trata un subproducto o epifenómeno de rasgos evolutivos como el ansia de estatus en el grupo o la capacidad de construir artefactos destinados a un fin (Pinker, 2002, 588); 
en este sentido, para Pinker "el arte es una tecnología de placer, como las drogas, el erotismo o la alta cocina" $(2002,588)$; pero, en cualquier caso, "tanto si es una adaptación, un subproducto o una mezcla de ambos, está enraizado profundamente en nuestras facultades mentales" $(2002,588)$. No obstante, este autor desgaja deliberadamente a la literatura de este tronco artístico (al menos a la literatura con un claro componente narrativo o ficcional) para asegurar que esta actividad en concreto 'sí es un producto directo de la evolución en la medida en que contribuyó a la supervivencia de nuestra especie:

Las personas son animales imaginativos que recombinan constantemente lo que ocurre en su mente. Esta capacidad es uno de los motores de la inteligencia humana, y nos permite concebir nuevas tecnologías (por ejemplo, cómo atrapar a un animal [...]) y nuevas destrezas sociales (por ejemplo [...] la identificación de enemigos comunes). La ficción narrativa emplea esta capacidad para explorar mundos hipotéticos, sea por edificación - para ampliar el número de escenarios cuyos resultados se puedan prever - sea por placer - para experimentar indirectamente el amor, la adulación, la exploración o la victoria-. $(2002,589)$

Tras esta aseveración de las cualidades adaptativas de la actividad literaria, Pinker, muy significativamente, alude a Horacio y a la finalidad que éste asigna a la literatura: "instruir y deleitar" (Pinker, 2002, 589).

\section{Conclusiones}

Tanto Joseph Carroll como Steven Pinker y Denis Dutton vienen a coincidir en que la actividad literaria tendría un origen y una explicación adaptativos - frente a otras propuestas como la de Stephen Jay Gould que la consideran una consecuencia azarosa de un proceso adaptativo previo, como es el crecimiento del cerebro-. En este sentido, la literatura no tendría esa cualidad que se le atribuye a partir de una lectura algo apresurada 
de Kant como carente de finalidad (Dutton, 2009, 150-151; Volpi, 2011, pos. 15), sino que, por el contrario, se enraizaría en una necesidad fundamental de los seres humanos, que queda "integrada en nuestra naturaleza a través de la evolución" y constituye además una de las cualidades mentales que nos separan de otras especies (Dutton, 2009, 155). Eso sí: siempre entendida esta actividad literaria en un sentido muy genérico $\mathrm{y}$, en cierto modo, embrionario, como causa última a la que vendrían a sumarse toda una serie de capas producto del desarrollo humano posterior y de otros intereses (algunos también evolutivos) confluyentes que le habrían proporcionado toda su variedad y complejidad posteriores, en un salto análogo al que se produce desde la necesidad reproductiva primordial al erotismo, también entendido en un sentido amplio. Su función estaría relacionada, según Carroll, con el desarrollo de una cartografía cognitiva en relación al medio, no solo físico, sino también social y cultural, en el que se desenvuelve la especie humana y donde, a través de un uso particular de la imaginación y del lenguaje, habría contribuido a la supervivencia de la especie y por consiguiente habría constituido una ventaja adaptativa. En este sentido, como sugieren Pinker y Dutton, serviría para explorar hipótesis, adelantar acontecimientos y proveerse de experiencias indirectas sin sufrir sus posibles consecuencias negativas. Estaría además dotada de una cualidad didáctica e informativa de carácter mnemotécnico con la que aprender cuestiones fundamentales - una de las cualidades que, de hecho, se le atribuye a la épica arcaica griega $-y$ además serviría para explorar los puntos de vista de otros seres humanos y comprenderlos, sus ideas, sus sentimientos y actitudes distintas de los nuestros y por tanto mejorar nuestra posibilidad de comunicación y cooperación con ellos; también nos permiten anticiparnos a sus reacciones en un apoyo a nuestra facultad (también evolutiva) de psicología intuitiva y comprensión de las reacciones ajenas.

La cualidad adaptativa de la literatura "se deriva de la capacidad que posee la mente humana para acumular experiencias 
a partir de casos concretos individuales, no solo de la vida real" (Dutton, 2009, 162), sino también de lo contado por otros (o lo leído), al margen de que haya sucedido realmente o no. Según un experimento llevado a cabo por el investigador Mbemba Jabbi, cuando un sujeto se enfrenta a una escena de la vida real o a una representación, incluso ficticia, se activan las mismas áreas cerebrales y se producen emociones semejantes, y además independientemente del formato, sea este textual o visual (Espada, 2008, 65; Volpi, 2011, pos. 1101). La importancia literalmente vital de la ficción puede comprenderse si se pone en relación con los juegos infantiles de ficción (Dutton, 2009, 153), vitales para el aprendizaje. Es preciso "resaltar la sofisticación espontánea e innata de los niños cuando fingen" $(2009,153)$. Resulta sorprendente, aparte de la relativa complejidad de estos juegos imaginativos ficticios, la capacidad de crear y hacer valer "normas y restricciones coherentes" - ese "como sí", o, "vale que esto era..." - que configuran un escenario (un mundo) verosímil, como en las mejores ficciones adultas y como "los niños también son capaces de separar con gran precisión los mundos de fantasía de los reales, y dejar en cuarentena múltiples mundos imaginarios de auténtica vida del mundo de verdad" $(2009,154)$.

Es cierto que, en estas apreciaciones, nuestros autores se refieren casi en exclusiva al ámbito de la ficción. No obstante, esto en realidad no supone un gran contratiempo. Algunos autores como Martínez Bonati y su idea del "hablar imaginario" o Pozuelo Yvancos (1997) han indicado como condición de partida de la literatura su cualidad ficcional o de palabra previa fingida. En concreto, para Pozuelo, el fenómeno literario

siempre presupone un hablante ficticio, necesario elemento de toda literatura, de modo que la separación de narración, drama y lírica nunca puede justificarse por la índole de su subjetividad o por la apariencia de ser la lírica más directamente expresiva del yo-hablante. $(1997,262)$ 
En realidad, esta consideración del hecho literario en términos evolutivos, desde su relativa novedad o modernidad, nos retrotrae de algún modo paradójico al origen de la reflexión teórica acerca de la literatura en Occidente, a la Poética de Aristóteles, donde, frente a la preeminencia posterior que se le irá confiriendo a sus peculiares cualidades lingüísticas - que llegará a su máxima expresión con el llamado 'giro lingüístico' -, la característica principal de este objeto que Aristóteles aún conoce con el nombre de 'Poesía' (esto es, 'creación') es en realidad la mímesis, esto es la capacidad de la imitación o representación imaginativa (1974, 1447a, 10). Aristóteles, a la luz de la teoría evolutiva, se presenta dotado de una profunda intuición acerca de la naturaleza del hecho literario - equivalente a la de Anaximandro cuando prefiguró la propia teoría evolutiva misma al postular que los organismos vivos evolucionaban unos a partir de otros en el tiempo a partir de un limo primigenio (Dutton, 2009, 125) - , y esto al menos en las siguientes ideas: 1) La ya citada fundamentación de la actividad poética como esencialmente representativa y, además, no de cualquier cosa, sino de las acciones humanas: "los que imitan, imitan a hombres que actúan" (Aristóteles, 1974, 1448a, 1). 2) La comprensión de la importancia de la imitación en su doble dimensión de una actividad que produce placer y de herramienta de aprendizaje (mencionando incluso la infancia): "el imitar, en efecto, es connatural al hombre desde la niñez, y se diferencia de los demás animales en que es muy inclinado a la imitación y por la imitación adquiere sus primeros conocimientos, y también el que todos disfruten con las obras de imitación" (1974, 1448b, 5); y más adelante, añade: "siéndonos, pues natural el imitar, así como la armonía y el ritmo [...] desde el principio los mejor dotados para estas cosas, avanzando poco a poco, engendraron la poesía partiendo de las improvisaciones" (1974, 1448b, 20). 3) Finalmente, en la idea de catarsis o expurgación de las pasiones, a partir de la cual le concede a la actividad poética una funcionalidad exploratoria de la realidad en sus posibilidades 
y la suscitación de pasiones vicarias: "mediante la compasión y el temor lleva a cabo la purgación de semejantes afecciones" (1974, 1449b, 25).

La hipótesis de la naturaleza evolutiva de la actividad literaria podrá o no ir confirmándose o, como parece lo más probable, nunca podrá demostrarse del todo. Desde las humanidades, podremos incluso cuestionar esta teoría u otras análogas provenientes del ámbito científico (o mejor, algunas consecuencias espurias que hayan podido extraerse de forma interesada de ellas). No obstante, no podemos seguir pretendiendo que no existen, o que no afectan a nuestro propio ámbito de estudio. En palabras de George Steiner, dirigidas a los humanistas, "si no entendemos algo mejor el lenguaje de las ciencias no podemos entrar en los grandes debates que se avecinan" (en Fernández Buey, 2013, 33). Pero, sobre todo, no podemos seguir soslayando, en cuanto humanistas, la teoría de la evolución, en la medida en que esta forma parte sustancial de la respuesta a la pregunta sobre quiénes somos y qué es lo que nos hace humanos.

\section{Referencias bibliográficas}

Aristóteles (1974), Poética, ed.V. García Yebra, Madrid, Gredos.

Asensi, M. (2003) Historia de la teoría de la literatura (el siglo Xx hasta los años setenta), Valencia, Tirant lo Blanch.

Bobes Naves, C. (2008) Crítica del conocimiento literario, Madrid, Arco/Libros.

Carroll, J. (1995) Evolution and Literary Theory, Columbia, University of Missouri Press.

Chicharro, A. (1987) Literatura y saber, Sevilla, Alfar.

Dupont, F. (1994) La invención de la literatura, Barcelona, Debate.

Dutton, D. (2009) El instinto del arte. Belleza, placer y evolución humana, Barcelona, Paidós.

Espada, A. (2008) Periodismo práctico, Barcelona, Espasa.

Fernández Buey, F. (2013) Para la tercera cultura. Ensayos sobre ciencias y humanidades, Barcelona, El Viejo Topo. 
Frye, N. (1977) Anatomía de la crítica, Caracas, Monte Ávila.

García Berrio, A. (1994) Teoría de la literatura (la construcción del significado poético), Madrid, Cátedra.

Gould, S. J. (1995) "El cuadro de la historia de la vida", en Brockman, J. (ed.), La tercera cultura. Más allá de la revolución científica, Barcelona, Tusquets, 47-68.

Jakobson, R. (1981) Lingüística y poética, Madrid, Cátedra.

James, H. (2007) Retrato de una dama, Madrid, Cátedra.

Kundera, M. (1986) El arte de la novela, Barcelona, Círculo de lectores.

Lotman, Y (1970) Estructura del texto artístico, Madrid, Istmo.

Pinker, S. (1995) "El lenguaje es un instinto humano", en Brockman, J. (ed.), La tercera cultura. Más allá de la revolución científica, Barcelona, Tusquets, 203-223.

Pinker, S. (2002) La tabla rasa. La moderna negación de la naturaleza humana, Barcelona, Paidós.

Pozuelo Yvancos, J. M. (1997) “Lírica y ficción”, en Garrido Domínguez, A. (comp.), Teorías de la ficción literaria, Madrid, Arco/Libros, 241-268.

ShкLоvski, V. (1965) "El arte como artificio", en Todorov, T. (ed.), Teoría de la literatura de los formalistas rusos, Buenos Aires, Ediciones Signos, 55-70.

Volpi, J. (2011) Leer la mente. El cerebro y el arte de la ficción, México D. F., Alfaguara, edición electrónica.

WAHNón, S. (1991) Introducción a la historia de las teorías literarias, Granada, Universidad de Granada. 